ISSN 0103-8478

\title{
Análise dialélica em mamoeiro para resistência a mancha-de-phoma
}

\author{
Diallel analysis of papaya for resistance to phoma spot
}

\section{Marcelo Vivas $^{\mathrm{I}^{*}}$ Silvaldo Felipe da Silveira $^{\mathrm{I}}$ Messias Gonzaga Pereira $^{\mathrm{II}}$ Deisy Lúcia Cardoso ${ }^{\mathrm{II}}$ Geraldo Antônio Ferreguetti ${ }^{\text {III }}$}

\section{RESUMO}

A resistência genética constitui alternativa sustentável para o controle da mancha-de-phoma na cultura do mamoeiro. No entanto, estudos básicos são necessários para a escolha de genitores e combinações híbridas resistentes à doença. Neste trabalho, por meio de cruzamento dialélico, envolvendo oito genótipos de mamão, quatro do grupo Solo e quatro do grupo Formosa, estimou-se a capacidade geral e especifica de combinações hibridas quanto à resistência a mancha-de-phoma. Os genitores, bem com os hibridos obtidos dos cruzamentos foram avaliados em blocos casualizados, com quatro repetições. Quantificaram-se em duas épocas, março e maio de 2010, as severidades de mancha-de-phoma em folha, com auxilio de escala diagramática. Os genótipos Maradol JS12-N, Sekati e São Mateus demonstram melhor capacidade geral de combinação. Os hibridos Maradol x Golden, Maradol x Sunrise Solo 72/12, JS12-N $x$ Golden, JS12-4 x Waimanalo, Sekati $x$ Waimanalo, Waimanalo x Golden, Waimanalo x São Mateus, Golden x Sunrise Solo 72/12 e Golden x São Mateus apresentaram resultados promissores para seleção quanto à resistência à doença, com valores negativos de capacidade especifica de combinação para severidade de mancha-de-phoma.

Palavras-chave: Phoma caricae-papayae, Carica papaya, hibridação.

\section{ABSTRACT}

Genetic resistance represents a viable alternative to control phoma-spot in papaya crop. However, basic studies are necessary to base the choice of genitors and hybrid combinations disease resistant. In this research, a diallel cross was conducted involving eight genotypes of papaya, four of the Solo group and four of Formosa group and it was estimated general and specific abilities of combination for the phoma-spot resistance. The treatments were evaluated in a randomized block design with four replications. The severity of phoma-spot in leaves was quantified in two ocasions: March and May of 2010. The genotypes Maradol JS12-N, Sekati e São Mateus show better general combining ability. The hybrids Maradol x Golden, Maradol x Sunrise Solo 72/12, JS12-N x Golden, JS12-4 x Waimanalo, Sekati $x$ Waimanalo, Waimanalo $x$ Golden, Waimanalo x São Mateus, Golden x Sunrise Solo 72/12 and Golden x São Mateus showed promising results for selection, with negatives values of specific combining ability for severity of phoma spot.

Key words: Phoma caricae-papayae, Carica papaya, hybridazation.

\section{INTRODUÇÃO}

O mamoeiro (Carica papaya L.) é uma das fruteiras tropicais de maior importância no Brasil. Atualmente, o Brasil é o segundo maior produtor mundial, ficando atrás somente da Índia, e o terceiro maior exportador da fruta. O mamão é a sétima fruta in natura mais exportada no País, sendo cultivado em cerca de 30 mil hectares, que estão concentrados nos estados do Espírito Santo, Bahia, Ceará e Rio Grande do Norte (AGRIANUAL, 2011).

Além dos fatores econômicos, existem outras importantes limitações à exportação do mamão brasileiro. Do ponto de vista fitossanitário, merece destaque a incidência de doenças na cultura, durante a fase de produção e na pós-colheita. Dentre as doenças mais importantes na fase de pós-colheita, destacam-se a antracnose, causada

\footnotetext{
'Laboratório de Entomologia e Fitopatologia,Universidade Estadual do Norte Fluminense Darcy Ribeiro (UENF), 28015-620, Campos dos Goytacazes, RJ, Brasil. E-mail: mrclvivas@hotmail.com. *Autor para correspondência.

"Laboratório de Melhoramento Genético Vegetal, UENF, Campos dos Goytacazes, RJ, Brasil.

IIICaliman Agrícola S.A., Linhares, ES, Brasil.
} 
pelo fungo Colletotrichum gloeosporioides Penz., e a podridão-peduncular, causada por diversos fungos (ALVAREZ \& NISHIJIMA, 1987), principalmente por $C$. gloeosporioides e Stagonosporopsis caricae (Sydow \& P. Sydow) Aveskamp, Gruyter \& Verkley [=Phoma caricae-papayae (Tar) Punith.] (LIBERATO \& TATAGIBA, 2001; REZENDE \& MARTINS, 2005; AVESKAMP et al. 2010). S. caricae (=P . caricaepapayae), na fase de produção, também causa a manchade-phoma, que é uma mancha foliar necrótica emergente nesta cultura no Brasil, exigindo mudanças nas técnicas de produção, dificultando o controle químico com fungicidas atualmente em uso na cultura do mamoeiro. Epidemias durante o crescimento vegetativo e na fase de frutificação geram inóculo que passa das folhas para os frutos, promovendo a incidência da podridãopeduncular em pós-colheita. Já se constatou incidência de $100 \%$ de podridão-peduncular em frutos, quando na ausência de quaisquer medidas de controle (LIBERATO \& COSTA, 1997). Atualmente, a podridão peduncular é considerada a segunda doença mais importante em póscolheita no Brasil (REZENDE \& MARTINS, 2005).

VIVAS et al. (2010) relata que $\boldsymbol{P}$. caricae papayae tem se mostrado de difícil controle em áreas comerciais do município de Linhares, Espírito Santo. Nessa região, a doença tem ocorrido com alta severidade nas folhas, aumentando o potencial de inóculo no campo. É sabido que o controle da epidemia da mancha-dephoma nas folhas reduz a incidência de podridão peduncular nos frutos em pós-colheita. SUZUKI et al. (2007) observaram redução de até $24 \%$ na incidência de podridão-peduncular, quando foi efetuada a sanitização, que consiste na remoção das folhas senescentes e doentes durante a frutificação.

Além da sanitização, outra medida de controle alternativo ao químico consiste no plantio de variedades resistentes. Não existem até o momento variedades comerciais resistentes à mancha-de-phoma que possam ser recomendadas. Alguns trabalhos já relatam, no entanto, variabilidade genética em Caricaceae quanto à resistência à mancha-de-phoma. SANCHEZ et al. (1991) avaliaram a reação à manchade-phoma em frutos de Carica goudotiana (Triana \& Planch.) Solms, Carica cauliflora Jacq (espécies reclassificadas atualmente no gênero Vasconcellea), duas cultivares ('Sunrise Solo 72/12' e 'Formoso') e quatro linhagens (DCG-434(4pa), DCG-422, DCG435-5 e $\mathrm{SS}_{2}$ ) de $\boldsymbol{C}$. papaya. Os autores observaram resistência à mancha-de-phoma em $\boldsymbol{C}$. goudotiana em condições de campo e em pós-colheita. VIVAS et al. (2010), em condições de campo, avaliaram a severidade e a incidência da mancha-de-phoma em banco de germoplasma e híbridos de mamoeiro e observaram variabilidade dentre os materiais avaliados, sendo os genótipos Maradol, Maradol GL, Papaya 46, Tailândia, SH 15-04, Americano e Baixinho de Santa Amália os que apresentaram as menores médias de intensidade de doença (VIVAS et al., 2010).

Entretanto, até o momento, nenhum genótipo foi identificado com resistência total ou imune à mancha-de-phoma. VIVAS et al. (2010; 2011) relatam a heterose em mamoeiro com potencial significativo para a redução da severidade da mancha-de-phoma, o que justifica o estudo dos genitores per se e em combinações híbridas, que possam ser promissores no controle da doença. Para tanto, o sistema de cruzamentos dialélicos constitui potente método de avaliação dos genótipos, pois, além de indicar as melhores combinações híbridas, auxilia na escolha dos genitores mais promissores em hibridação (CRUZ et al., 2004).

Neste trabalho, avaliou-se, por meio de cruzamentos dialélicos, as capacidades geral e específica de combinação (CGC e CEC) quanto à resistência à mancha-de-phoma, causada por $\boldsymbol{S}$. caricae (=P. caricae-papayae), bem como o efeito recíproco de oito genótipos de mamoeiro, quatro do grupo 'Solo' e quatro do grupo 'Formosa', com o intuito de se desenvolver cultivares e, ou híbridos de mamoeiro resistentes à mancha-de-phoma.

\section{MATERIAL E MÉTODOS}

Foi instalado um experimento em esquema dialelo completo, envolvendo oito genitores, quatro do grupo Formosa (Maradol, JS12-N, JS12-4 e Sekati) e quatro do grupo Solo (Waimanalo, Golden, Sunrise Solo 72-12 e São Mateus). O experimento foi implantado no ano de 2009, na empresa Caliman Agrícola S/A, em Linhares, ES.

As 64 combinações (Genitores, $\mathrm{F}_{1}$ 's e recíprocos) foram avaliadas em delineamento estatístico em blocos ao acaso, com quatro repetições, sendo cada parcela composta de 10 plantas (duas fileiras de cinco plantas cada). O espaçamento, em fileira dupla, foi de 3,6m entre linhas, $2 \mathrm{~m}$ entre fileiras e $1,8 \mathrm{~m}$ entre plantas. A irrigação, do tipo microaspersão, foi suprida conforme as necessidades e os tratos culturais foram como recomendamos para a cultura do mamoeiro (MARIN et al., 1995).

A parcela útil consistiu de três plantas centrais, escolhidas ao acaso em caminhamento em $\mathrm{W}$, quantificando-se a severidade de mancha-dephoma (SMP) na folha localizada imediatamente 
abaixo da folha com a axila anexa a primeira flor aberta. A severidade foi estimada visualmente com auxílio de escala diagramática adotada por VIVAS et al. (2010).

Efetuou-se análise de variância conjunta dos dados, considerando-se além de cruzamentos, época de avaliação como fonte de variação. Quando constatado efeito significativo da interação genótipo $\mathrm{x}$ época, foram conduzidas análises separadas para cada época. As somas de quadrados só foram desmembradas em capacidade específica e geral de combinação quando constatado efeito significativo de genótipo. Nas análises de capacidade combinatória, foram incluídos os genitores, os híbridos $F_{1}$, assim como os recíprocos, perfazendo o total de $\mathrm{p}^{2}$ genótipos. Considerou-se para análise o Modelo 1 de GRIFFING (1956). Todas as análises foram feitas utilizando o programa genes (CRUZ, 2006).

\section{RESULTADOS E DISCUSSÃO}

Observou-se efeito significativo de todas as fontes de variação testadas (genótipo, época de avaliação e interação genótipo x época). Como houve efeito da interação genótipo x época, procedeu-se análises separadas, para cada época de avaliação. Observou-se efeito significativo da fonte de variação genótipo para as duas épocas de avaliação (Tabela 1). Para cada época, as somas dos quadrados das médias dos tratamentos (genótipos) foram decompostas em capacidade geral (CGC) e específica de combinação (CEC) e efeito recíproco (Recíproco), conforme o Modelo 1, proposto por GRIFFING (1956).
Os valores dos quadrados médios referentes à CGC e CEC foram significativos para as características relacionadas à severidade da mancha-de-phoma em folha, notadamente na segunda avaliação, indicando que efeitos gênicos aditivos e não aditivos estão envolvidos no controle dessa característica (Tabela 1). Nas duas épocas de avaliação, não houve significância do efeito de recíproco (Tabela 1), sugerindo que a direção em que se faz o cruzamento não interfere na resistência observada no híbrido. A não ocorrência de efeito recíproco permite ao pesquisador trabalhar com um número menor de cruzamentos, uma vez que não há influência de qual genitor que será utilizado como masculino e feminino, sobre a manifestação da característica.

A significância para CGC indica que efeitos gênicos aditivos estão envolvidos. A existência de efeitos gênicos aditivos para a característica avaliada indica a possibilidade de obtenção de novas cultivares a partir de cruzamentos com os genitores testados (RAMALHO et al., 1993). Dessa forma, os genitores com valores mais elevados de CGC poderão ser selecionados para compor programas de melhoramento genético, no qual o objetivo é a seleção de linhagens derivadas de populações segregantes a partir de cruzamentos com os parentais testados (CARVALHO et al., 1999). Uma vez que se trata de resistência, os genótipos que apresentam CGC negativa são potencialmente superiores quanto à sua contribuição em programas de melhoramento. Dessa forma, os genótipos Maradol JS12-N, Sekati e São Mateus apresentaram as melhores estimativas

Tabela 1 - Estimativas dos quadrados médios da capacidade geral de combinação (CGC), da capacidade específica de combinação (CEC), do efeito recíproco (E. Rec), e média dos quadrados dos efeitos para severidade de mancha-de-phoma em folha de mamoeiro em duas épocas de avaliação, de acordo com o Método 1, Modelo 1, de Griffing. Linhares, Espírito Santo, 2010.

\begin{tabular}{|c|c|c|c|}
\hline \multirow{2}{*}{ Fonte de variação } & \multirow{2}{*}{ Grau de liberdade } & \multirow[b]{2}{*}{ Época I } & \multirow[b]{2}{*}{ Época II } \\
\hline & & & \\
\hline Genótipo & 63 & $3,3699 * *$ & $2,7118 * *$ \\
\hline CGC & 7 & $9,4563 * *$ & $9,4839 * *$ \\
\hline CEC & 28 & $2,8884^{\mathrm{ns}}$ & $2,6268 * *$ \\
\hline Recíproco & 28 & $2,3297^{\mathrm{ns}}$ & $1,1037^{\mathrm{ns}}$ \\
\hline Resíduo & 189 & 2,0833 & 1,0156 \\
\hline \multicolumn{4}{|c|}{ Média dos quadrados dos efeitos } \\
\hline C.G.C. & & 0,1152 & 0,1323 \\
\hline C.E.C. & & 0,2013 & 0,4028 \\
\hline Recíproco & & 0,0308 & 0,0110 \\
\hline Resíduo & & 2,0833 & 1,0156 \\
\hline
\end{tabular}

**Significativo em nível de $1 \%$ pelo teste $\mathrm{F}$; *Significativo no nível de $5 \%$ pelo teste $\mathrm{F}$; e ${ }^{\mathrm{ns}}$ Não significativo pelo teste $\mathrm{F}$.

Ciência Rural, v.43, n.6, jun, 2013. 
de capacidade geral de combinação, nas duas épocas de avaliação. Enquanto os genótipos JS-12-4 e Sekati apresentaram estimativa negativa de capacidade geral de combinação, quando avaliados, respectivamente, na primeira e na segunda época de avaliação desse experimento (Tabela 2).

Segundo GRIFFING (1956), as melhores combinações devem possuir altos valores de capacidade específica de combinação e altas estimativas de CGC. BASTOS et al. (2003) relatam que efeitos relacionados à $\mathrm{CEC}$ enfatizam a importância de interações não aditivas resultantes de complementações gênicas entre os parentais, possibilitando antever respostas de ganho genético com a exploração da heterose. Considerando o objetivo do trabalho (resistência genética), as combinações mais favoráveis devem ser, portanto, aquelas que apresentarem menores estimativas de capacidade específica de combinação.

Considerando a estimativa de capacidade específica de combinação, na primeira época de avaliação, os híbridos com valores negativos para severidade de mancha-de-phoma em folha foram: Maradol x Sekati (-0,236), Maradol x Golden $(-1,181)$, Maradol x Sunrise Solo 72/12 (-0,408), Maradol x São Mateus (-1,318), JS 12-N x Sekati $(-0,190)$, JS 12-N x Golden (-0,235), JS 12-4 x Sekati $(-0,410)$, JS 12-4 x Waimanalo $(-0,431)$, Sekati $\mathrm{x}$ Waimanalo $(-0,490)$, Waimanalo x Golden $(-0,600)$, Waimanalo x São Mateus (-0,062), Golden x Sunrise Solo 72/12 (-0,691) e Golden x São Mateus $(-0,426)$. $\mathrm{Na}$ segunda época de avaliação, os 16 híbridos que

Tabela 2 - Estimativas dos efeitos de capacidade geral de combinação para severidade de mancha-de-phoma estimada em folha (SMP) em duas épocas de avaliação, de oito genitores de mamoeiro. Linhares, ES, 2010.

\begin{tabular}{lcc}
\hline & ----Capacidade Geral de Combinação---- \\
& Época I & Época II \\
\hline Maradol & $-0,204$ & $-0,545$ \\
JS 12-N & $-0,300$ & $-0,072$ \\
JS 12-4 & $-0,545$ & 0,011 \\
Sekati & 0,009 & $-0,215$ \\
Waimanalo & 0,055 & 0,622 \\
Golden & 0,499 & 0,371 \\
Sunrise Solo $72 / 12$ & 0,586 & 0,187 \\
São Mateus & $-0,099$ & $-0,358$ \\
DP (Gi) & 0,168 & 0,118 \\
DP (Gi-Gj) & 0,255 & 0,178 \\
\hline
\end{tabular}

apresentaram estimativas negativas de capacidade específica de combinação foram: Maradol x JS 12-N $(-0,073)$, Maradol x Waimanalo (-0,647), Maradol x Golden (-0,181), Maradol x Sunrise Solo 72/12 $(-0,117)$, JS $12-\mathrm{N}$ x JS 12-4 (-0,064), JS 12-N x Golden (-0,715), JS 12-N x Sunrise Solo 72/12 $(-0,460)$, JS $12-7$ x Waimanalo $(-0,638)$, JS 12-4 x Golden (-0,203), Sekati x Waimanalo $(-0,192)$, Sekati x Golden (-0,671), Waimanalo x Golden (-0,374), Waimanalo x São Mateus (-0,185), Golden x Sunrise Solo 72/12 (-0,214), Golden x São Mateus $(-0,424)$ e Sunrise Solo 72/12 x São Mateus (-0,315) (Tabela 3).

Das estimativas de capacidade específica de combinação dos híbridos, considerando as duas épocas de avaliação, os que apresentaram valores negativos de CEC para severidade de mancha-dephoma em folha foram: Maradol x Golden, Maradol x Sunrise Solo 72/12, JS12-N x Golden, JS12-4 $\mathrm{x}$ Waimanalo, Sekati x Waimanalo, Waimanalo x Golden, Waimanalo x São Mateus, Golden x Sunrise Solo 72/12 e Golden x São Mateus.

Dos híbridos supracitados, IDE et al. (2009) apontaram que Golden x JS12-N resultou em plantas com alta inserção do primeiro fruto, se comparado com os outros híbridos. Ademais, produziu um número grande de frutos e com peso médio elevado, resultando em plantas com alto rendimento. Porém, apresentou baixos valores de sólidos solúveis totais e firmeza de polpa. Os autores identificaram ainda que o cruzamento entre o testador JS 12 e genótipo São Mateus pode ser usado em seleção, devido às boas características morfológicas, de rendimento e qualidade. Quanto ao genótipo Waimanalo, MARIN et al. (2006) afirmam que este apresenta tendência de maior contribuição genética para aumento do peso do fruto. Os mesmos autores afirmam, ainda, que o genótipo Maradol demonstrou tendência de maior contribuição genética para o aumento do peso do fruto, enquanto Sunrise Solo 72/12 poderá ser utilizado visando à obtenção de híbridos com menor peso.

Com base nos dados obtidos, acredita-se que a característica que confere resistência à manchade-phoma apresenta herança poligênica e genes agindo de forma independente. Aventa-se, ainda a possibilidade de se explorar heterose. Dessa forma, acredita-se ser mais durável o tipo de resistência que se pretende buscar, o que não impede que a população do patógeno possa se adaptar ao novo genótipo ao longo do tempo, no caso de um plantio extenso e intensivo de um determinado híbrido. Assim, novos estudos deverão ser conduzidos no sentido de se estudar a herança da resistência dos híbridos mais promissores, bem como a variabilidade do patógeno 
Tabela 3 - Estimativas dos efeitos de capacidade específica de combinação resultantes do cruzamento entre genitores de mamão, quanto à severidade da mancha-de-phoma estimada em folha.

\begin{tabular}{|c|c|c|c|c|}
\hline \multirow{2}{*}{ Híbrido Avaliado } & \multirow[b]{2}{*}{$\mathrm{F}_{1} \mathrm{~S}$} & \multirow[b]{2}{*}{ Recíproco } & \multirow[b]{2}{*}{$\mathrm{F}_{1} \mathrm{~S}$} & \multirow[b]{2}{*}{ Recíproco } \\
\hline & & & & \\
\hline Maradol x JS 12-N & 0,968 & 0,095 & $-0,073$ & 0,045 \\
\hline Maradol x JS 12-4 & 0,468 & 0,690 & 0,064 & 0,165 \\
\hline Maradol x Sekati & $-0,236$ & 0,810 & 0,255 & $-0,150$ \\
\hline Maradol x Waimanalo & 0,532 & 0,315 & $-0,647$ & 0,245 \\
\hline Maradol x Golden & $-0,181$ & 0,875 & $-0,181$ & 0,430 \\
\hline Maradol x Sunrise Solo 72/12 & $-0,408$ & $-0,185$ & $-0,117$ & 0,090 \\
\hline Maradol x São Mateus & $-1,318$ & 0,460 & 0,173 & 0,165 \\
\hline JS $12-\mathrm{N}$ x JS $12-4$ & 0,030 & 0,055 & $-0,064$ & 0,410 \\
\hline JS 12-N x Sekati & $-0,190$ & $-0,100$ & 0,017 & $-0,075$ \\
\hline JS 12-N x Waimanalo & 0,014 & $-0,690$ & 1,230 & 1,005 \\
\hline JS 12-N x Golden & $-0,235$ & 0,875 & $-0,715$ & 0,090 \\
\hline JS 12-N x Sunrise Solo 72/12 & 0,554 & $-0,130$ & $-0,460$ & $-0,080$ \\
\hline JS 12-N x São Mateus & 0,029 & 0,130 & 0,115 & 0,500 \\
\hline JS 12-4 x Sekati & $-0,410$ & $-0,015$ & 0,604 & 0,365 \\
\hline JS 12-4 x Waimanalo & $-0,431$ & $-0,470$ & $-0,638$ & $-0,050$ \\
\hline JS $12-4$ x Golden & 0,100 & 0,605 & $-0,203$ & 0,095 \\
\hline JS $12-4$ x Sunrise Solo 72/12 & 0,064 & $-0,655$ & 0,157 & 0,780 \\
\hline JS 12-4 x São Mateus & 0,879 & 1,235 & 0,007 & 0,015 \\
\hline Sekati x Waimanalo & $-0,490$ & $-0,395$ & $-0,192$ & $-0,820$ \\
\hline Sekati x Golden & 0,631 & 0,100 & $-0,671$ & $-0,160$ \\
\hline Sekati x Sunrise Solo 72/12 & 0,034 & 0,120 & 0,073 & 0,260 \\
\hline Sekati x São Mateus & 0,569 & 0,420 & 0,118 & 0,030 \\
\hline Waimanalo x Golden & $-0,600$ & 0,095 & $-0,374$ & 0,175 \\
\hline Waimanalo x Sunrise Solo 72/12 & 0,178 & 0,290 & 0,495 & 0,670 \\
\hline Waimanalo x São Mateus & $-0,062$ & 0,015 & $-0,185$ & $-0,235$ \\
\hline Golden x Sunrise Solo 72/12 & $-0,691$ & 0,185 & $-0,214$ & 0,100 \\
\hline Golden x São Mateus & $-0,426$ & $-1,235$ & $-0,424$ & 0,135 \\
\hline Sunrise Solo 72/12 x São Mateus & 0,772 & 0,250 & $-0,315$ & $-0,315$ \\
\hline DP (Sij) e DP (Rij) & 0,451 & 0,510 & 0,315 & 0,356 \\
\hline DP (Sij-Skl) e DP (Rij-Rkl) & 0,625 & 0,722 & 0,436 & 0,504 \\
\hline
\end{tabular}

quanto à virulência. Caso se observe efeito raçacultivar ou interação significativa entre genótipoisolado em estudos de inoculação sob condição controlada, novas combinações híbridas e outras fontes de resistência deverão integrar o programa de melhoramento.

\section{CONCLUSÃO}

As estimativas de capacidade combinatória podem ser usadas para selecionar genitores e híbridos potencialmente promissores para gerar cultivares mais resistentes a $\boldsymbol{S}$. caricae (=P. caricae-papayae). Com base nos resultados, pode-se destacar os genitores Maradol JS12-N, Sekati e São Mateus e seus respectivos híbridos Maradol x Golden, Maradol x Sunrise Solo 72/12, JS12-N x Golden, Sekati x
Waimanalo, Waimanalo x São Mateus e Golden x São Mateus.

\section{AGRADECIMENTOS}

A Fundação Carlos Chagas Filho de Amparo à Pesquisa do Estado do Rio de Janeiro (FAPERJ), a Universidade Estadual do Norte Fluminense Darcy Ribeiro (UENF) e a Caliman Agrícola S/A pelo suporte financeiro e logístico.

\section{REFERÊNCIA}

AGRIANUAL (ANUÁRIO DA AGRICULTURA BRASILEIRA). Mamão. São Paulo: FNP Consultoria e Comércio, 2011, 482p.

ALVAREZ, A.M.; NISHIJIMA, W.T. Post harvest diseases of papaya. Plant Disease, v.71, p.681-686, 1987. Disponível em: $<$ http://www.apsnet.org/publications/PlantDisease/BackIssues/ Documents/1987Articles/PlantDisease71n08_681.pdf >. Acesso em: 23 abr. 2012.

Ciência Rural, v.43, n.6, jun, 2013. 
AVESKAMP, M.M. et al. Highlights of the Didymellaceae: A polyphasic approach to characterise Phoma and related pleosporalean genera. Studies in Mycology, vol. 65, p.1-60, 2010. Disponível em: $<$ http://www.ncbi.nlm.nih.gov/pmc/articles/ PMC2836210/>. Acesso em : 10 de Dez. 2012. doi: 10.3114/ $\operatorname{sim} .2010 .65 .01$.

BASTOS, I.T. et al. Análise dialélica em clones de cana-deaçúcar. Bragantia, v.62, p.199-206, 2003. Disponível em: $<$ http://www.scielo.br/scielo.php?script=sci_arttext\&pid=S000687052003000200004\&lng=pt\&nrm=iso $>$. Acesso em: $14 \mathrm{dez}$. 2011. doi: 10.1590/S0006-87052003000200004.

CARVALHO, A.C.P.P. et al. Capacidade de combinação para oito caracteres agronômicos em cultivares de feijão-de-vagem de crescimento determinado. Horticultura Brasileira, v.17, p.102105, 1999.

CRUZ, C.D. et al. Modelos biométricos aplicados ao melhoramento genético II. Viçosa: UFV, 2004. 480p.

CRUZ, C.D. Programa genes, biometria. Viçosa: UFV, 2006. 377p.

GRIFFING, B.A. Concept of general and specific combining ability in relation to diallel crossing systems. Australian Journal of Biological Sciences, v.9, p.463-493, 1956. Disponível em: $<$ http://www.publish.csiro.au/?act=view_file\&file_id=BI9560463. pdf>. Acesso em: 30 jan. 2009. doi: 10.1071/BI9560463.

IDE, C.D. et al. Use of testers for combining ability and selection of papaya hybrids. Crop Breeding and Applied Biotechnology, v.9, p.60-66, 2009. Disponível em: <http://www.sbmp.org.br/ cbab/siscbab/modules/news/article.php?storyid=589>. Acesso em: 12 fev. 2009.

LIBERATO, J.R.; COSTA, H. Incidência de antracnose e podridão peduncular em frutos de mamoeiro em Linhares, ES. Fitopatologia Brasileira, v.22, p.276, 1997 (suplemento).

LIBERATO, J.R.; TATAGIBA, J.S. Avaliação de fungicidas in vitro e em pós-colheita para o controle da antracnose e da podridão peduncular em frutos de mamão. Summa Phytopathologica, v.26, p.409-414, 2001.
MARIN, S.L.D. et al. Partial diallel to evaluate the combining ability for economically important traits of papaya. Scientia Agricola, v.63, p.540-546, 2006. Disponível em: <http:// www.scielo.br/scielo.php? script $=$ sci_arttext\&pid $=$ S0 $103-$ $90162006000600005 \& \operatorname{lng}=\mathrm{pt} \& \mathrm{nrm}=\mathrm{iso}>$. Acesso em: 20 mar. 2008. doi: 10.1590/S0103-90162006000600005.

MARIN, S.L.D. et al. Recomendações para a cultura do mamoeiro dos grupos Solo e Formosa no Estado do Espírito Santo. 4.ed. Vitória: EMCAPA, 1995. Circular Técnica 3.

RAMALHO, M.A.P. et al. Genética quantitativa em plantas autógamas, aplicações ao melhoramento do feijoeiro. Goiânia: UFG, 1993. 271p.

REZENDE, J.A.M.; MARTINS, M.C. Doenças do mamoeiro. In: KIMATI, H. et al. (Eds.). Manual de fitopatologia. Doenças das plantas cultivadas. São Paulo: Ceres, 2005. V.2, p.435-443.

SANCHEZ, M. et al. Fatores determinantes do dano de Phoma caricae-papayae ao fruto do mamoeiro (Carica papaya) e detecção de resistência ao fungo em Carica gaudotiana. Fitopatologia brasileira, v.16, p.121-129, 1991.

SUZUKI, M.S. et al. Progresso de doenças fúngicas e correlação com variáveis climáticas em mamoeiro. Summa Phytopathologica, v.33, p.167-177, 2007. Disponível em: $<$ http://www.scielo.br/scielo.php?script $=$ sci_arttext\&pid $=$ S0100$54052007000200011 \& \operatorname{lng}=\mathrm{em} \& \mathrm{nrm}=\mathrm{iso} \& \operatorname{lng}=\mathrm{pt}>$. Acesso em: 20 nov. de 2011. doi: 10.1590/S0100-54052007000200011.

VIVAS, M. Reação de germoplasma e híbridos de mamoeiro à mancha-de-phoma (Phoma caricae-papayae) em condições de campo. Tropical Plant Pathology, v.35, p.323-328, 2010. Disponível em: $<$ http://www.scielo.br/scielo.php?script $=$ sci arttext\&pid $=\mathrm{S} 1982-56762010000500009 \& \operatorname{lng}=\mathrm{pt} \& \mathrm{nrm}=$ iso $\&$ tlng $=\mathrm{pt}>$. Acesso em: 20 mar. 2011. doi: 10.1590/S198256762010000500009 .

VIVAS, M. Testers for combining ability and selection of papaya hybrids resistant to fungal diseases. Crop Breeding and Applied Biotechnology, v.11, p.36-42. 2011. Disponível em: $<$ http://www.scielo.br/scielo.php?script=sci arttext\&pid=S1984$70332011000100005 \& \operatorname{lng}=\mathrm{pt} \& \mathrm{nrm}=\mathrm{iso} \& \operatorname{tlng}=\mathrm{e}=\mathrm{e}>$. Acesso em: 20 mar. 2011. doi: 10.1590/S1984-70332011000100005. 